\title{
Pre-Mathematical Training of Educational and Intellectual Skills for Preschoolers
}

\author{
Eshonkulova Masuda Khabibovna ${ }^{1}$, Dzhumaev Mamanazar Irgashevich ${ }^{2}$ M. \\ Yoserizal Saragih ${ }^{3}$ \\ ${ }^{1}$ Doctoral Student at Gulistan State University, Uzbekistan \\ ${ }^{2}$ Professor at the Tashkent State University named after Nizami, Tashkent City, Uzbekistan \\ ${ }^{3}$ Universitas Islam Negeri Sumtera Utara, Indonesia \\ mamanazaruz@bk.ru
}

\begin{abstract}
In the decree of the Government of the Republic of Uzbekistan. The goal of the strategy, designed for 2017-2021, is to radically increase the effectiveness of the reforms, create conditions for the comprehensive and accelerated development of the state and society, implement priority directions for the modernization of the country and liberalize all spheres of life. As you know, in almost all countries of the world, the basis for modernization of the country, innovation in the education system becomes a priority. Only through education can we move on to a new path of development both in science and in production. Creation of a highly effective system of professional higher education in the search and application of a qualitatively new educational and scientific system that meets the modern requirements of the spirit of the time. It is gratifying to note that until now, changes in the system of education and science have occurred in accordance with the historical realities of the whole world, in particular our country. In order to maintain a unified educational space, to implement the continuity of state standards at all levels and levels of education. The theoretical foundations of solving the problem of the formation of intellectual skills are widely represented in a number of psychological and pedagogical studies. Conclusions and recommendations on the formation of skills of didactic activity of an elementary school teacher are proposed.
\end{abstract}

Keywords component; formation; thinking; intellect

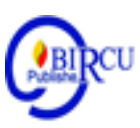

\section{Introduction}

In the decree of the Government of the Republic of Uzbekistan. The goal of the strategy for 2017-2021 is to radically increase the effectiveness of ongoing reforms, create conditions for ensuring the comprehensive and accelerated development of the state and society, implement priority areas for modernizing the country and liberalize all spheres of life.

The action strategy will be implemented in five stages, each of which provides for the approval of a separate annual State program for its implementation in accordance with the announced name of the year. Development of the social sphere, aimed at consistently increasing employment and implementing targeted programs for the development of education, culture, science, literature, art and sports, improving state youth policy; "Development of the social sphere of the Republic of Uzbekistan" [5] defines the main directions of the development of education at school and approaches to teaching, implying the orientation of education to the formation of general intellectual, universal skills, 
methods of activity that have a practice-oriented orientation (competence-based approach to learning). In determining the selection and location of the educational content of schoolchildren, it is essential to assess the development trends of mathematical education.

As is known in almost all countries of the world, innovations in the education system become a priority in the modernization of the country. Only through education can one switch to a new path of development both in science and in production. Creation of a highly effective system of professional higher education for the search and application of a qualitatively new educational and scientific system that meets the modern requirements of the spirit of the times [1-2]. The education system for any society is the basis for the cultural and spiritual reproduction of itself; it is in this area that society lays down its future.

Education in its upbringing essence is addressed to the main wealth of children, the younger generation, and youth. It is gratifying to note that until now, changes in the education and science system have been taking place in accordance with the historical realities of the whole world, in particular our country. Over the years of independence, Uzbekistan has created a powerful educational and scientific base, in particular, 118 higher educational institutions functioned, 7 of which were branches of leading universities of foreign countries (Russia, England, Italy, Singapore, Korea, China), according to the decree of the President of the Republic of Uzbekistan Sh.M. Mirziyoyev on the further improvement of the higher education system since September 2017, seven more universities have begun to operate. In 2018, it is planned to create 5 more higher educational institutions in technical sciences. Preparatory work is underway to create a branch of MGIMO in Tashkent.

\section{Review of Literatures}

About 46 thousand people carry out scientific research work in the republic. Among them - 2.8 thousand doctors of sciences, - more than 16, 100 candidates of sciences. Highly qualified scientific personnel are trained in more than 20 branches of science. In the republic, research was carried out in the most modern scientific areas in the field of nuclear energy, biotechnology, plant genetics, virology, polymer chemistry and chemistry of alkaloids, astronomy [1-7].

The development of the preschool education system, which is the main and at the same time the most important link in education, is constantly in the center of attention of the head of our state. In order to reform and improve the system, a number of decrees and resolutions of the President of the country were adopted.

In particular, the decree "On approval of the Concept for the development of the system of preschool education of the Republic of Uzbekistan until 2030" to ensure greater coverage of children with preschool education, replenishment of preschool organizations with modern teaching materials and literature, attracting qualified personnel.

And so, At present, the general direction of modernization and improvement of the learning process leads to a reduction in reproductive, traditional methods and the introduction of new, more modern and effective ones, during which the student becomes an active participant in the learning process. Erkin Ergashevich Zhumaev proposed a system of specific exercises as a means of forming logical knowledge and skills, studying concepts and actions, revealing the connections between them in first graders.

Thanks to the orienting basis of actions, the child masters the logic of actions and reasoning. He recognizes object images, compares, establishes their similarity, 
distinguishes or identifies, compares, compares, analyzes (the whole splits into parts), performs synthesis (makes up the whole from parts), draws an analogy, abstracts (from insignificant features), classifies, generalizes. His logical thinking develops. In this case, mental structures are formed involuntarily, gradually.

A.M. Matyushkin notes that the problem of using psychological patterns of thinking in order to improve teaching methods is often replaced by the problem of "teaching thinking", teaching general methods, logical methods of thinking. But the assimilation of the methods of thinking themselves occurs all the same in accordance with the psychological laws of assimilation. The development and improvement of teaching methods, including logical methods of thinking, depends on the extent to which they correspond to the psychological laws of the assimilation process.

In our case, the learning process is adequate to the mathematical image, the child does not learn anything mechanically. The volume of his memory is growing, interest in mastering concepts, mental reactions are fast and critical, imagination becomes creative. All mental processes in general develop.

The main tasks of the pre-mathematical training of children in a preschool institution are:

1. Formation of a system of elementary mathematical concepts among preschoolers. To solve this problem, the child needs to master the program for the development of elementary mathematical concepts.

2. Formation of prerequisites for mathematical thinking and individual logical structures necessary for mastering mathematics at school and general mental development in children. The prerequisites for mathematical thinking, their process is built taking into account the level of development of visual-effective and visual-figurative thinking of the preschooler and the transition to more abstract forms of orientation in the environment (from the concrete to the abstract).

3. Formation of sensory processes (perception, presentation) and abilities (observation, eye).

4. Expanding children's vocabulary and improving coherent speech.

5. Formation of the initial forms of educational activity among preschoolers

To solve the above tasks, you need:

1. Tasks of teaching preschoolers to the elements of mathematics in kindergarten.

2. General characteristics of the content of the pre-mathematical training of children in kindergartens.

The practical method in the lesson of mathematics is the leading one. Its essence lies in organizing the practical activities of children:

- performing a variety of practical exercises;

- widespread use of didactic material;

- development of ideas about forthcoming activities;

- formation of computing skills;

- the use of mathematical concepts in practice, in everyday life. reproductive nature and the choice of subject-object relationships in the learning process.

The success of training largely depends on the conditions in which it takes place.

We have determined that educational and intellectual skills and literacy can be developed most effectively in the conditions of student-centered learning, built on the basis of subject-subject relationships between participants in the pedagogical process. This creates the preconditions for the disclosure of the essential forces of students, their intellectual potential, the ability to independently develop their own activity. 
As you know, the organization of such training requires a change in the teacher's professional position, the creation of an atmosphere of "free learning" in the classroom, the use of methods that stimulate the student's activity and his development. Therefore, among the conditions for the development of educational and intellectual skills, the following were singled out: orientation to the humanistic principles of education in the process of educational activity, the implementation of a system of lessons on the problem of the development of educational and intellectual skills of younger students, the use of an optimal combination of teaching methods and forms of educational work in the system of lessons [8- 12].

One of the system-forming elements is the goal - the formation of specific educational and intellectual skills in junior schoolchildren, contributing to the effective formation of the ability to self-organize knowledge, as the basis for their successful learning in the middle and senior level of school and mastering a synergistic style of thinking.

It should be noted that various forms of educational work and ways of combining them make it possible to differentiate educational activities for various categories of students, to diversify tasks so as to make it feasible for each student. It is also very important for the development of motivation for learning, independence, self-control, intellectual activity [16-20].

The technology for constructing an indicative basis of actions was developed in the theory of educational cycles of school education. It shows how to organize the stage-bystage mental activity of a student to acquire mathematical knowledge right in the classroom. How to organize thematic repetition of school mathematics in university preparation courses has been shown in our previous studies [7]. And how should one determine the child's adequate activity based on picture tasks?

The kid on the drawing should be led with a story, a fairy tale, history, indicating the guidelines for the step-by-step development of the mathematical image and the formation of intellectual skills and abilities. By providing the child with an indicative basis for mental actions, we eliminate the variety of intermediate stages, which means we eliminate the errors characteristic of each of them, and reduce the time to solve the problem. Orientation helps to identify the stepwise transformation of perceptual and mental actions. Thanks to the indicative action base, it is easy to perform step-by-step control and ensure the baby's transition to self-control. Consider a problem with an indicative action framework provided. Over the past thirty ears, many reforms have been carried out in the education of intellectually, physically perfect youth. Mathematics is identified as one of the priority areas for the development of science in our country in 2020. Over the past period, a number of systematic works have been carried out aimed at raising mathematical science to a qualitatively new level.

Preparation of future primary school teachers, improvement of their efficiency are necessary for the serious attitude of young students' towards the determination of their way of independently thinking and the goals of life. That's why, it is very important to inculcate into students' mind right norms of social relationships and an imagination about criteria which will protect them from taking unprecedented actions [1-3].

The basic principles of intellectual (scientific) development: the definition of types of intellectual activity as a subject of special assimilation, adequate visuality, provision of indicative foundations of mental actions, adequate operation on demand of pictures different from new conceptual approaches to the formation of elementary mathematical concepts in young children. 
The next pedagogical condition for the development of educational and intellectual skills, which are the basis for the formation of the ability to self-organize knowledge of younger students, we have identified the development and implementation of a system of lessons.

\section{Discussion}

Analysis of didactic literature shows that the structure and methodology of lessons at school largely depend on those didactic goals and tasks that are solved in the process of studying a particular topic. This allows us to talk about the methodological variety of lessons and highlight those that are characterized by a number of common features.

The specificity of the lesson system lies in the fact that each lesson combines the study of a new one, repetition in the form of updating previous knowledge, abilities and skills, the formation of new concepts and methods of activity and control of the assimilation of the educational material of the entire topic as a whole in the course of its application by schoolchildren in solving practical and educational tasks in the lesson.

One of the system-forming elements is the goal - the formation of specific educational and intellectual skills in junior schoolchildren, contributing to the effective formation of the ability to self-organize knowledge, as the basis for their successful learning in the middle and senior level of school and mastering a synergistic style of thinking. The next pedagogical condition for the development of educational and intellectual skills, which are the basis for the formation of the ability to self-organize knowledge of younger students, we have identified the development and implementation of a system of lessons.

Analysis of didactic literature shows that the structure and methodology of lessons at school largely depend on those didactic goals and tasks that are solved in the process of studying a particular topic. This allows us to talk about the methodological variety of lessons and highlight those that are characterized by a number of common features.

The specificity of the lesson system lies in the fact that each lesson combines the study of a new one, repetition in the form of updating previous knowledge, abilities and skills, the formation of new concepts and methods of activity and control of the assimilation of the educational material of the entire topic as a whole in the course of its application by schoolchildren in solving practical and educational tasks in the lesson.

It is important to note that in didactics, the problem of the forms of educational work and the construction of methods in various forms of educational work is still insufficiently developed. Analysis of research in the field of psychology and pedagogy, aimed at studying the issues of teaching primary school students, showed that in the work of teachers with students of this age, a large role is given to verbal, visual and practical methods. Play methods and techniques, as in preschool age, retain their importance. Among the forms of educational work, frontal and individual predominate.

In order to further improve the system of teaching mathematical science at all levels of education, to support the effective work of teachers, to expand the scale and practical importance of scientific research, strengthen ties with the international community, and also fulfill the tasks identified in the State Program for the Implementation of the FiveStep Action Strategy priority areas of development of the Republic of Uzbekistan in 2017 2021 in the "Year of the development of science, education and the digital economy"[1]: 
Identify the priority areas of improving the quality of education, the development of scientific research and the implementation of scientific developments in the field of mathematics:

- the formation of a holistic system that ensures close cooperation between preschool, general secondary, specialized secondary, professional, higher educational and scientific institutions;

- -the introduction of modern pedagogical technologies for the formation of initial mathematical representations in preschool children on the basis of advanced foreign experience;

- -improving the quality of teaching mathematical sciences in general and secondary special educational institutions, the development in the regions of specialized schools with in-depth study of mathematics, as well as the creation of new schools;

- - the development of a system of training and retraining of mathematics personnel, in particular in schools located in rural areas, the improvement of textbooks and teaching aids in mathematics;

- identification of talented youth, ensuring its successful participation in republican and international mathematics Olympiads and winning prizes;

- the creation and implementation of an educational online platform, increasing the effectiveness of the distance education system, introducing mechanisms to ensure the transparency of the assessment system;

- implementation of the National certification system for assessing the level of knowledge in mathematics, increasing classes and improving the quality of education in mathematics in the relevant areas and specialties of higher education;

- ensuring continuous communication with the production of scientific research in the field of mathematics, the development of applied mathematics and the development of mathematical solutions based on modeling problems in economic sectors;

- support for talented young people studying and engaged in scientific research, development of relations with foreign higher educational institutions and scientific organizations in the field of mathematics;

- stage-by-stage bringing of scientific and educational organizations of our country to the level of leading world scientific centers in mathematics.

In accordance with the new concept, the content and methods of teaching students have been adjusted. The results of the correction are reflected in the programs "Bolajon", "Ilk qadam". Experiment takes 2017-2020. In the city of Tashkent, Gulistan, Temez, Bukhara, Feragana and other cities of Uzbekistan.

Starting this research, we set ourselves the goal: to develop and substantiate a conceptual approach to the formation of elementary mathematical concepts in young children.

Analysis of scientific mathematical, psychological and methodological literature on the problem of the formation of elementary mathematical representations in preschool children and primary school children, mathematical education programs for children in kindergarten and primary school, training programs for the future educator and primary school teacher in terms of mathematics made it possible to develop and substantiate a set provisions defining a conceptual approach to teaching young children. The content of the child's intellectual development is corrected as scientific, as a result of learning in the logic of science with the help of adequate visibility and presentation of the indicative basis of 
actions. The principle of adequate operation on a picture task has been developed using the stage-by-stage formation of mental actions.

The fundamental course "Mathematics" is distinguished as a theory of mathematical training. Its feature is becoming integrative: each level of the course content is considered from the point of view of the need to study it for subsequent practical use in teaching children 3-11 years old. The highlighted graph of the logical structure of the integrated course provides the student with an understanding of the prospects for his study, activates the position, provides knowledge that goes far beyond the scope of primary school education. The intellectual activity of a young child is the basis for the choice of content, determination of the goal and the result of the mathematical training of a student, a future teacher of a children's educational institution and a primary school teacher.

As a procedural component of mathematical training, a methodological teaching system has been developed as a source of awareness of the mechanisms of formation of elementary mathematical concepts in young children.

The highlighted mathematical content of the student's mathematical training based on the construction of a graph of the logical structure of three disciplines of the curriculum allows you to organize the study at the level of elementary portions of educational material. A test can serve as an objective measure for assessing the quality of knowledge. Obtaining the required coefficient of assimilation of knowledge is an objective result (goal) of assimilation of theoretical knowledge, which is specified when organizing control in the traditional way at exams and tests.

The real educational process of a pedagogical university considers lectures and classroom practical exercises to be the main form of education. Traditional teaching methods are used in organizing the educational process in effective didactic systems. A distinctive feature of such an organization is stable and long-term feedback and a directed information process. This is ensured by a system of developed teaching aids, including textbooks and teaching aids; mathematical dictations; notebooks with a printed base; cards of general and individual tasks; graphic and settlement and graphic works; control sections; tests, etc. As a procedural component of mathematical training, a methodological teaching system has been developed as a source of awareness of the mechanisms of formation of elementary mathematical concepts in young children.

The highlighted mathematical content of the student's mathematical training based on the construction of a graph of the logical structure of three disciplines of the curriculum allows you to organize the study at the level of elementary portions of educational material. A test can serve as an objective measure for assessing the quality of knowledge. Obtaining the required coefficient of assimilation of knowledge is an objective result (goal) of assimilation of theoretical knowledge, which is specified when organizing control in the traditional way at exams and tests.

The real educational process of a pedagogical university considers lectures and classroom practical exercises to be the main form of education. Traditional teaching methods are used in organizing the educational process in effective didactic systems. A distinctive feature of such an organization is stable and long-term feedback and a directed information process. This is ensured by a system of developed teaching aids, including textbooks and teaching aids; mathematical dictations; notebooks with a printed base; cards of general and individual tasks; graphic and settlement and graphic works; control sections; tests, etc. 
The efficiency of using the fundamentals of subjects learnt by students at universities in practice requires the following conditions:

- Making preparation for the developing pedagogical culture in students;

- Preparing high-qualified primary school teachers, satisfying personal interests, developing trust;

- Induce internal motivation and interest to learn

- Legislation documents should be respected; train qualifications and experience; motivate students to fight against having no education.

- Work out the directions of methodic readiness of future primary school children which contributes to the development of students as creative persons.

Solving these problems contributes to the developing great mathematical ideas within the school mathematics, enriching mathematical factology with humanitarian domains, finding various examples to mathematical information, the abstract appearance of mathematics in the environment, linking it with human activity, especially, with students' one, observing existing, but rarely coming out mathematical cases, which are beautiful and interesting cases.

It means that in developing professional, especially, methodic skills and experience practice works and its appropriate didactic formation teach to think logically and creatively, analyze cases and facts, establish one's independent own work, helps to show good results at education process, gives an intellectual character to the whole studying and learning process.

One of the main directions of our conception compiles of determination of the meaning of the course "Mathematical methodic" which is linked to the mathematics of primary school; determination of connection of methodical and mathematical education; encourage individual approach of primary school teachers to teaching mathematics; acquiring mathematical scientific research methods by primary school teachers; training teachers to choose mathematical materials which help students to acquire new information; the problems connected with acquisition of an experience by primary school teachers which helps to form a whole understanding about the environment which contributes to the development of a creative student.

The program on the subject of "the Methodic of Teaching Mathematics" was renewed; first time when in our Republic a textbook called "Lab Practices on the Methodic of Teaching Mathematics" has been published. It contains such skills which enriched with such ideas as by humanizing the meaning of education, an idea of new primary education which develops creative primary schoolchildren. For acquiring new skills by lab practice way, future primary school teachers using alternative methods of solving problems, will get to know their efficiency, sensitivity, their descriptive character, and reliance and when working with children they rely on those methods. They base students' activities on their individual character, subjective experience and descriptive quality [5].

Primary school children are considered to be a subject who has preliminary creative characteristics. Developing a schoolchild as a creative person requires taking into account the synthesized period of the development of the quality of creative character or its components. In teaching primary schoolchildren mathematics acquiring an individual approach by conditions is a warranty of developing a creative person with maximum efficiency.

Teachers' knowledge on psychological and pedagogical fundamentals of teaching primary schoolchildren mathematics helps to develop the operations of thinking in students provides a conscious approach of teachers in solving problems connected with the ways of thinking and acquiring in students. This in turn, contributes to the development of a 
student as a creative person. In particular, it is very important to educate pedagogues the methodic of teaching schoolchildren some significant primary mathematical conceptions, teaching them to think appropriately, developing skills, solving alternative problems.

Choosing the material which helps a primary schoolchild to imagine the material thoroughly, understand it and bring it to light is based on the followings:

- By the ways of checking the object to teach him/her to think versatile and by the means of plans, to use different methods of analysis in solving problems;

- Teaching the object to choose and solve the problems which require conscious changing; to create a new object (deeply thinking about the meaning);

- Teaching to create such problems which require getting information from other sources, using different types of activity, using direct and indirect way of thinking together, looking through different cases, using different methods of accomplishment;

- In working with students to teach primary school pedagogues the transfer of real items to geometric models, to carry out the transfer from those models to undefined geometric items, to study space figures, to develop unique forms of activity; to teach the methodic of solving problems connected with dividing the figures into parts and making up different figures from those parts, to teach to divide items into parts consciously and making up a whole item from those parts.

- Preparing pedagogues to teach students conscious operations, ways of thinking, e. g. using them in obtaining information, developing reflection, e. g. understanding motivation for obtaining information in children.

During every lesson for efficient development of students besides the main subjects, knowing the identified domain unofficially is required. Talking about unofficial knowledge, we mean not only knowing thoroughly the chosen mathematical module, but also understanding its professional value, believing into the efficiency of the primary schoolchildren's learnt materials. Special and elective courses are considered to be the main component part of teaching mathematics. In identifying the themes of supplementary courses, we rely on the analysis of the meaning of mathematics of primary course, methodic of teaching mathematics, the analysis of the meaning of mathematical courses in primary schools, the tendency of renewing and completing the mathematical courses, taking the Governmental Standards into account, professional activity of a future primary school teacher. Special courses and optional courses for students: "Activities and Their Introduction", "The Methodic of teaching students making up geometric items", "Solving Non-Standard Problems as the Development of Students' Creativeness". These are used by future primary school teachers for working out compositional optional subjects [6].

The given course prepares future primary school teachers to develop an optional subject system for developing creativeness of students during mathematical lessons. But, this is carried out mostly during optional lessons. On optional lessons a teacher relies on time less and students feel themselves more independently and have communicative relations with each other. Our special courses and optional courses help a student to acquire needed methodic- mathematical preparation.

The system of optional science of this special course compiles of three goals: 1) increases mathematical degree, enlarges the volume of skills integrated on the special course of mathematics; 2) increases the methodic fundamental, acquires methodic skills; 3) the material of this special course should be connected with the primary school mathematical course, the ways of acquiring, as for the ways of acquiring them, they should be linked to the methodical ways used in primary schools. Preparation for working out the system of extra classes based on the learnt materials which are connected with a whole 
mathematical idea which contains the elements of innovation and as much as possible the ones of history, aesthetics and which has various applications and acquired skills help primary school teachers to accomplish it.

In the system of preparing primary school teachers within the primary educational faculties on special and elective courses one should pay much attention to geometry. Its main characteristics are compiled of the followings: relying on the visual way of thinking, imagining with the help of space, imagination, intuition, a student's methodicmathematical preparation:

- It requires a non-standard approach to solving geometric problems;

- Solving geometric problems by the means of geometric instruments. This is of a great importance, because, a teacher usually does not have time for such things; so, the development of geometric imagination in students is carried out with the help of practical activity;

- Working with geometric instruments contributes to the formulation of practical skills in students. Here their feeling and aesthetic activities are considered to be a fundamental. Moreover, working with geometric instruments increases students' interest;

Actually studying geometric materials compiles of an imagination which helps students to connect life experience and intuition, different feelings (from the feeling of having knowledge up to the feeling happy to know it), with non- mathematical spheres and the imagination which is known to a student in routine life (nature, living conditions, the environment, the world, music, dance, applications, carpets, colorful paper and etc.). Materials for teaching children have been developed in line with the new conceptual approach. Experimental and experimental work of students with children on books and sets of didactic games was carried out.

In the course of the research, the essence of the theoretical and methodological components of student training was highlighted as a set of provisions that determine the conceptual approach to teaching. The student's mathematical training is understood as a movement from the formal existence of theory and methodology to an organically holistic combination of mathematical and methodological lines. The criterion for the mathematical preparedness of a graduate student for pedagogical activity is the level assessment of his professional qualities: worldview, skill, behavior. Materials for teaching children have been developed in line with the new conceptual approach. Experimental and experimental work of students with children on books and sets of didactic games was carried out.

In the course of the research, the essence of the theoretical and methodological components of student training was highlighted as a set of provisions that determine the conceptual approach to teaching. The student's mathematical training is understood as a movement from the formal existence of theory and methodology to an organically holistic combination of mathematical and methodological lines. The criterion for the mathematical preparedness of a graduate student for pedagogical activity is the level assessment of his professional qualities: worldview, skill, behavior.

Designing an effective educational process using a complete system of developed teaching aids that ensure the teacher's work in didactic mesosystems at lectures and practical classes, guarantees the assimilation of knowledge at the level of algorithmic activity. To bring a student to the level of creativity, it is necessary to use integral technologies.

The prerogative is given to the organization of independent work of students. They build graphs of logical structures and alternative programs; make up tests for kids and 
schoolchildren; make up picture tasks; develop didactic games; design albums with educational tasks; come up with computer games; prepare reports and abstracts; keep diaries of observations when teaching children; describe their teaching experience, etc. Some of the students write term papers and qualification papers, publish articles in collections of scientific papers. For effective teaching of students, educational materials have been developed, including the textbook "Mathematics".

The development of an integral system of student's mathematical training served as the basis for methodological recommendations on how to build a system of integrated training in any subject.

In accordance with the new concept of the formation of elementary mathematical concepts in young children, the content and methods of teaching students have been adjusted, a monograph and a book for parents and educators have been published.

In the course of the study, all the tasks were solved: scientific mathematical, psychological, pedagogical and methodological literature, mathematical education programs in kindergarten and elementary school, training programs for a student of the faculty of primary grades and preschool education in terms of disciplines of the mathematical cycle were analyzed; developed and substantiated a set of provisions defining a conceptual approach to teaching children; scientific and methodological support for teaching children in line with a new conceptual approach has been developed, the essence of the theoretical and methodological components of the student's mathematical training has been identified and substantiated; the content and methods of teaching students have been adjusted in accordance with the new concept of the formation of elementary mathematical concepts in young children. To bring a student to the level of creativity, it is necessary to use integral technologies.

Teaching a child on intellectual (scientific) tasks on the basis of adequate visualization with the provided indicative basis of actions, we will define as the principle of adequate operation.

Adequate operation on picture tasks develops the ability to work with concentration for a long time, listen to the teacher, follow the course of his reasoning, and bring the work started to the end. Making up its orienting basis for mental and perceptual actions, the child essentially experiments, actively explores, which in turn activates his attention and mental activity, contributes to their long-term and effective unification - "polarization" (M. Montessori). The prerogative is given to the organization of independent work of students. They build graphs of logical structures and alternative programs; make up tests for kids and schoolchildren; make up picture tasks; develop didactic games; design albums with educational tasks; come up with computer games; prepare reports and abstracts; keep diaries of observations when teaching children; describe their teaching experience, etc. Some of the students write term papers and qualification papers, publish articles in collections of scientific papers. For effective teaching of students, educational materials have been developed, including the textbook "Mathematics".

The development of an integral system of student's mathematical training served as the basis for methodological recommendations on how to build a system of integrated training in any subject.

In accordance with the new concept of the formation of elementary mathematical concepts in young children, the content and methods of teaching students have been adjusted, a monograph and a book for parents and educators have been published.

In the course of the study, all the tasks were solved: scientific mathematical, psychological, pedagogical and methodological literature, mathematical education programs in kindergarten and elementary school, training programs for a student of the 
faculty of primary grades and preschool education in terms of disciplines of the mathematical cycle were analyzed; developed and substantiated a set of provisions defining a conceptual approach to teaching children; scientific and methodological support for teaching children in line with a new conceptual approach has been developed, the essence of the theoretical and methodological components of the student's mathematical training has been identified and substantiated; the content and methods of teaching students have been adjusted in accordance with the new concept of the formation of elementary mathematical concepts in young children.

\section{Conclusions}

Analysis of didactic literature shows that the structure and methodology of lessons in primary school largely depend on those didactic goals and tasks that are solved in the process of studying a particular topic. This allows us to talk about the methodological variety of lessons and highlight those that are characterized by a number of common features. The problem of the development of the intellectual skills of the student in elementary school has long and fruitfully been developed in psychology and pedagogy.

Obviously, it can be concluded that didactics have not sufficiently developed the application of partial search, problematic and other methods of teaching younger students; organization of individualized, paired, unit forms of educational work; the problem of constructing the optimal combination of teaching methods in different forms of educational work.

As a result of the work carried out, we have established that the methods and forms of educational work are closely associated with the mental activity of schoolchildren, cognitive interest and independence. This, in turn, directly affects the development of educational and intellectual skills and the ability to independently organize the process of assimilation of knowledge, which are based on the same characteristics.

Thus, the inclusion of schoolchildren in active work based on the humanistic principles of education, and the use of the lesson system, taking into account the use of an optimal combination of teaching methods and forms of educational work, will significantly expand the teaching and educational opportunities of the lesson and will contribute to the development of literacy and educational and intellectual skills in younger students.

The requirements to the created special course are the followings:

1. In studying the mathematical course relying on the informative material.

2. The fundamental of this special course should include one of the leading mathematical ideas.

3. The chosen idea should correspond to primary school.

4. The special course should be professionally valuable for a student.

5. The meaning of the special course should be practically directed.

6. In the special course the connection knowledge with other spheres especially, with the spheres which are not concerned to mathematics should be considered.

7. The meaning of the special course should be important not only for the meaning of factual materials, but also in the methodic-mathematical preparation of a student the intellectual activities, (intellectual operations, the ways of thinking, the ways of intellectual activity), other methodic ways (for giving examples to mathematical conceptions using guide-books, the elements of role-playing, cases of "or-or" and etc.). 
8. In the acquiring the special course the taken preparation should determine the variation system of compositional subjects for students which carries out the aim of teaching, methods, ways, and means.

9. Within the framework of the special course endowment of future primary school teachers with the efficient accomplishment of high-school diploma and master's degree works should be provided.

10. The professional who wants to establish the special courses should provide the preparation of future primary teachers.

Firstly, in the special course the lack of the proportion of geometric materials is connected with the usage of different ways in teaching it and the importance of developing a creative person. In using geometric materials, a child relies on the intuition of understanding the world, his/her subjective experience, the development of objective components of thinking. The objective component of thinking is considered to be the main, and it is used for the progressive development of theoretical discussion. Secondly, connections with the idea of special integrated course, including other spheres of mathematics, such things as imagination, fantasy appear which concern to a child. So, it includes in the theory of changing some problems of the conception, constructive geometry, and non-standard problems.

\section{References}

1. Resolution of the president of the republic of uzbekistan/On measures to improve the quality of education and development of scientific researches in the field of mathematics /g. Tashkent, May 7, 2020, No. PP-4708.

2. Strategy of action in five priority areas of the development of the Republic of Uzbekistan in 2017-2021. to the Decree of the President of the Republic of Uzbekistan dated February 7, 2017 No. UP-4947

3. A whole program to improve the quality of education, increase the efficiency and practical significance of scientific research in the mathematical sciences in the Republic of Uzbekistan for 2020 - 2023. Tashkent, May 7, 2020, No. PP-4708

4. Assessing Reading, Mathematics and Scientific Literacy: A framework for PISA 2009. OECD, 2009.

5. OECD (2013), PISA 2012 Assessment and Analytical Framework: Mathematics, Reading, Science, Problem Solving and Financial Literacy, OECD Publishing.

6. Keunho Lee. Competency-based curriculum and curriculum autonomy in the Republic of Korea. UNESCO International Bureau of Education. Geneva-2014

7. Mathematics curriculum, Teacher Professionalism, and Supporting Policies in Korea and United States/ U.S. National Commission on mathematics. Instruction. Board of International Scientific Organizations. National Academies Press-2015.

8. Mathematics syllabuses. Curriculum planning and development division, Singapore Ministry of education. 2015

9. Character and Citizenship Syllabuses. Framework for $21^{\text {st }}$ Century competencies and Student outcomes. Student development curriculum division, Singapore Ministry of education. 2016 .

10. The National School Curriculum, Curriculum and Assessment Guide. CDC-HKEAA Committee. Hong Kong. http//www.emb.gov.hk/cr 
11.Ginsburg A., Lei wand S., and Decker K., "Informing Grades 1-6 Standards Development: What Can Be Learned from High-Performing Hong Kong, Korea, and Singapore?" American Institutes for Research, 200.

12.California Common Core State Standards. Mathematics. Electronic Edition. Adopted by the California State Board of Education August 2010 and modified January 2013. ISBN 978-0-8011-1748-8.

13. Zhumaev M.E. Methods of teaching mathematics for elementary grades: a Textbook. Turon Ikbol. Tashkent, 2016 .-- 426 p.

14. Davydov V.V. The psychological theory of educational activities and methods of elementary education, based on a meaningful generalization. - Tomsk, 1992 .-$112 \mathrm{p}$.

15. BirCI: http://www.bircu-ournal.com/index.php/birci

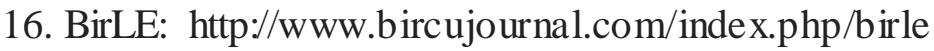

17. Konfrontasi: http://www.konfrontasi.net/index.php/konfrontasi2

18. Siasat: https://siasatjournal.com/index.php/siasat

19. Nurgazina A.B., Rakhimzhanov K.H., Akosheva M.K., Baratova M.N. Sakenov J. About the poetic text and a concept as ways of representation of author's subjectivity and modality. International Journal of Environmental and Science Education, 2016, VOL. 11, NO. 18, p. 11757-11770.

20. M.I. Zhumaev Formation of the didactic business skillsof the teacher in elemen tary school Department of primary education,Tashkent State Pedagogical Uni versity named after Nizami, Tashkent city, Republic of Uzbekistan

21. Zhumaev.E.E., Dzhuraeva D.Sh. Duning mathematician manzarasining modeli yasash masalalari // Muғallim xam uzluksiz bilimlenduriy̆. Ilmiy is a Nazarene journal. No. 3. -2017. Nukus. -B.130-135.

22. Zhumaev E.E., Aituvganov U.Kh. Mathematics and tourism as a means of developing creative thinking among students. // SCIENCE AND WORLD. International scientific journal. Volgagrad. No. 2 (78), 2020, Volume 2. B.22-25.

23. Zhumaev EE A small cometary to a large definition of the bisector of the angle, triangle and tetrahedron. // The Usa Jurnal of Applied Sciences. Sektion 2. Matematiks. 2016. - No. 2. -B.6-9.

24. Zhumaev E. C. Structural components of the creative activity of students of the Faculty of Physics and Mathematics. // BULLETIN of Psychology and Pedagogy of Altai State University. Scientific and theoretical journal. Krasnadar. 2016. - No. 3. -B.1 $-8$

25. Zhumaev E.E. and Aituvganoa U.Kh. The main objectives of the continuing education system in the XXI century. // Problems of modern education | Moscow State Pedagogical University, ISSN 2218-8711 ,. Moscow. 2016. - No. 5. -B.80 - 84. 